\title{
Beryl Reference Materials for In Situ Oxygen Isotope Determination
}

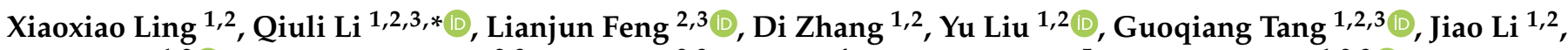 \\ Shitou $\mathrm{Wu}^{1,2}{ }^{10}$, Liangliang Huang ${ }^{2,3}$, Tiejun $\mathrm{Li}^{2,3}$, Yan Liu ${ }^{4}$, Ronald Werner ${ }^{5}$ and Xianhua $\mathrm{Li}^{1,2,3}$ \\ 1 State Key Laboratory of Lithospheric Evolution, Institute of Geology and Geophysics, Chinese Academy of \\ Sciences, Beijing 100029, China; lingxx@mail.iggcas.ac.cn (X.L.); zhangdi@mail.iggcas.ac.cn (D.Z.); \\ liuyu@mail.iggcas.ac.cn (Y.L.); tgq@mail.iggcas.ac.cn (G.T.); lijiao@mail.iggcas.ac.cn (J.L.); \\ shitou.wu@mail.iggcas.ac.cn (S.W.); lixh@gig.ac.cn (X.L.) \\ 2 Innovation Academy for Earth Science, Chinese Academy of Sciences, Beijing 100029, China; \\ ljfeng@mail.iggcas.ac.cn (L.F.); huangll@mail.iggcas.ac.cn (L.H.); litj@mail.iggcas.ac.cn (T.L.) \\ 3 College of Earth and Planetary Sciences, University of Chinese Academy of Sciences, Beijing 100049, China \\ 4 Institute of Geology, Chinese Academy of Geological Sciences, Beijing 100037, China; ly@cugb.edu.cn \\ 5 Evje og Hornnes Geomuseum Fennefoss, Postboks 24, N-4748 Rysstad, Norway; \\ ronald.werner@setesdalsmuseet.no \\ * Correspondence: liqiuli@mail.iggcas.ac.cn
}

Citation: Ling, X.; Li, Q.; Feng, L.; Zhang, D.; Liu, Y.; Tang, G.; Li, J.; Wu, S.; Huang, L.; Li, T.; et al. Beryl Reference Materials for In Situ Oxygen Isotope Determination. Crystals 2021, 11, 1322. https:// doi.org/10.3390/cryst11111322

Academic Editor: Vladislav V. Gurzhiy

Received: 29 September 2021

Accepted: 26 October 2021

Published: 29 October 2021

Publisher's Note: MDPI stays neutral with regard to jurisdictional claims in published maps and institutional affiliations.

Copyright: (c) 2021 by the authors. Licensee MDPI, Basel, Switzerland. This article is an open access article distributed under the terms and conditions of the Creative Commons Attribution (CC BY) license (https:// creativecommons.org/licenses/by/ $4.0 /)$.

\begin{abstract}
The mineral beryl $\left(\mathrm{Be}_{3} \mathrm{Al}_{2}\left(\mathrm{SiO}_{3}\right)_{6}\right)$ has the most abundant phase with industrial value for extracting a critical metal-beryllium. Due to multi-stage, fluid-induced growth, individual beryl grains may yield complex geochemical records, revealing variations in the oxygen isotopes of the fluids from which they crystallize. Secondary ion mass spectrometry (SIMS) with high sensitivity and high spatial resolution represents a good tool for in situ isotopic analysis. SIMS oxygen analyses require matrix-matched reference materials to calibrate instrumental mass fractionations during measurement. In this work, the oxygen isotope homogeneities of six beryl samples with different compositions (BS1, BS2, BS3, BS4, BS5, and BS6) were documented by SIMS. These samples' recommended oxygen isotope compositions were characterized by laser fluorination isotope ratio mass spectrometry (IRMS). This study suggests that there is no matrix effect related to composition variation in beryl SIMS oxygen isotope analysis. The recommended $\delta^{18} \mathrm{O}$ values of the four reference materials, BS1, BS2, BS4, and BS5, were $15.01 \pm 0.34 \%$ (2 standard deviations, 2 SD), $7.53 \pm 0.16 \%$ o (2SD), $2.38 \pm 0.14 \%$ o (2 SD), and $10.72 \pm 0.44 \%$ o (2 SD), respectively. Therefore, BS1, BS2, BS4, and BS5 are recommended as suitable reference materials for in situ mineral beryl oxygen isotope microanalysis.
\end{abstract}

Keywords: beryl; oxygen isotope; SIMS; matrix effect; reference materials

\section{Introduction}

One of the most significant current discussions regarding critical metals is that of beryllium (Be) [1,2]. Beryl $\left(\mathrm{Be}_{3} \mathrm{Al}_{2}\left(\mathrm{SiO}_{3}\right)_{6}\right)$ is definitely the most common manifestation of Be enrichment, as well as the most plentiful of the phases that contain Be [3,4]. In recent years, researchers have shown an increasing interest in beryl's composition, genesis, and geochemical characteristics [5-7]. Oxygen isotopes, which play a critical role in addressing geochemical evolution processes, have attracted considerable interest [8-10]. Beryl's mineral oxygen isotopes could be influenced by the composition and temperature of fluids and/or rocks. According to previous studies, the oxygen isotopic compositions of emerald (a variety of beryl) from different occurrences and deposits are variable. They may provide a good fingerprint of the origin of this kind of beryl [11]. In addition, due to multi-stage fluid-induced growth, an individual beryl grain may yield complex isotopic composition, revealing variations in the oxygen isotopes of the fluids from which beryl crystallized [12]. 
Secondary ion mass spectrometry (SIMS) with high sensitivity and high spatial resolution represents a good tool for in situ beryl analysis. However, the SIMS matrix effect generated by a mismatch between the matrix of the samples being analyzed and that of the standards used to calibrate instrumental mass fractionation (IMF) may cause incorrect results [13]. The matrix effects associated with $\mathrm{Fe}-\mathrm{Mg}$-exchangeable minerals (such as olivine, dolomite, and garnet) have been reported [14-16]. Because of matrix effects, matrixmatched reference materials or a suitable fractionation law to calibrate IMF is required during SIMS oxygen isotope measurement $[17,18]$. As for beryl, the iron content could vary from 0.1 to $3 \mathrm{wt} . \%$ [19]. The shortage of in situ reference materials (RMs) for beryl causes an ambiguous matrix effect, hindering in situ oxygen isotope research.

In this study, six SIMS beryl samples with different chemical compositions (BS1, BS2, BS3, BS4, BS5, and BS6) were examined by Raman spectroscopy and an electron microprobe. Their oxygen isotopic homogeneities were demonstrated by SIMS analyses. These samples' recommended oxygen isotope compositions were characterized by laser fluorination isotope ratio mass spectrometry (IRMS). Our work indicated that there is no observable composition-related matrix effect in SIMS beryl oxygen isotope analyses. Four natural beryl mineral samples are recommended as suitable reference materials for in situ oxygen isotopic composition microanalysis.

\section{Samples}

Six potential beryl RMs, including BS1, BS2, BS3, BS4, BS4, and BS6, as listed in Table 1, were investigated in this study.

Table 1. The beryl samples used in this work.

\begin{tabular}{ccccc}
\hline Sample & Location & Color & Transparency & Weight/Gram \\
\hline BS1 & Sichuan, China & Colorless to pale blue & Transparent & 15 \\
BS2 & Norway & Light greenish-blue & Transparent & 15 \\
BS3 & Hunan, China & Greenish-white & Semitransparent & 12 \\
BS4 & Nigeria & Colorless & Transparent & 15 \\
BS5 & Myanmar & Light pink & Transparent & 10 \\
BS6 & Brazil & Light blue & Transparent & 10 \\
\hline
\end{tabular}

The BS1 beryl sample, including two beryl crystals (BS1-1 and BS1-2), was isolated from one specimen, previously investigated by Liu et al. [20]. They were collected from a hydrothermal W-Sn-Be deposit in Xuebaoding, Sichuan Province, western China. These crystals were colorless transparent to pale blue, with a well-crystallized tabular habit (Figure 1a). The two crystals weighed approximately $15 \mathrm{~g}$. The BS2 beryl was a megacrystal collected from Norway, which was light greenish-blue, transparent, and weighed $15 \mathrm{~g}$ (Figure 1b). The BS3 beryl was separated from a pegmatite rock from Hunan, China (Figure 1c). This sample was semitransparent greenish-white and had lots of cracks. The BS4, BS5, and BS6 crystals were purchased from mineral dealers, collected from Nigeria, Myanmar, and Brazil, respectively. Their exact provenances and petrological characteristics are unknown. The BS4 megacrystals were colorless and transparent, with a total weight of $\sim 15 \mathrm{~g}$. The crystals were approximately $1-2 \mathrm{~cm}$ in their most extended dimensions and contained a few sub-parallel fractures but no visible inclusions (Figure 1d). The BS5 crystals, weighing approximately $10 \mathrm{~g}$, were light pink and transparent (Figure 1e). The BS6 crystals, weighing around $10 \mathrm{~g}$, were light blue and clean (Figure 1f). 


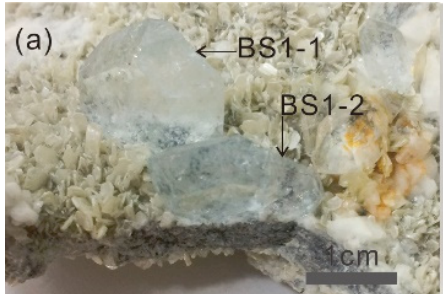

(d) (b)

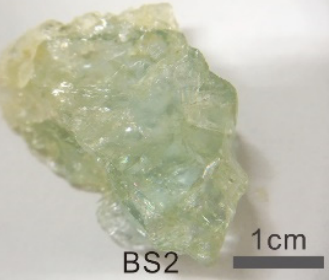

(e) (c)

(f)

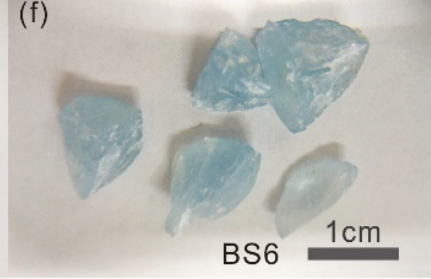

Figure 1. Hand specimens of beryl crystals were used in this study: (a) BS1 (including two crystals, BS1-1 and BE1-2) from Sichuan, China; (b) BS2 from Norway; (c) BS3 from Hunan, China; (d) BS4 from Nigeria; (e) BS5 from Myanmar; (f) BS6 from Brazil.

All of the megacrystals were crushed into tiny shards of around $0.1-1 \mathrm{~mm}$. The small fragments were colorless and transparent. Backscattered electron (BSE) images revealed that these shards were homogeneous (Figure 2), except for some cracks in BS3 and BS5 and quartz inclusions in BS3 (Figure 2c,f).

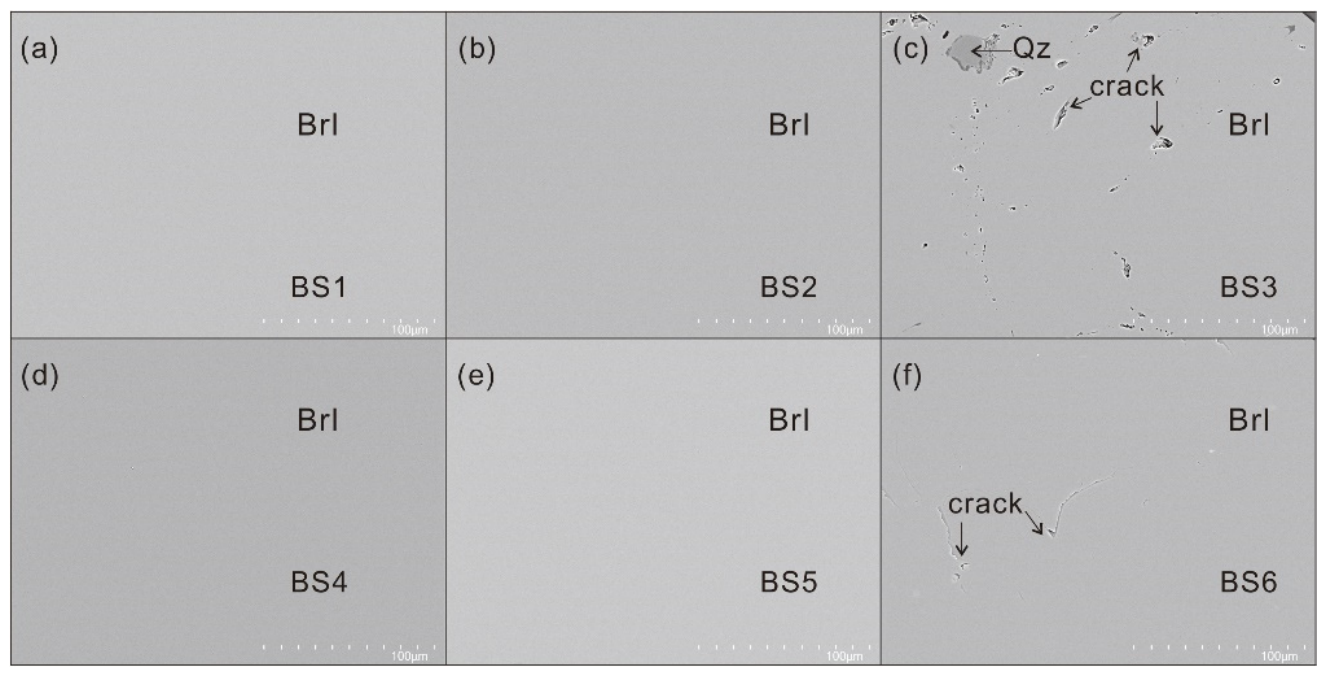

Figure 2. Representative BSE images of the beryl samples used in this study: (a) BS1, (b) BS2, (c) BS3, (d) BS4, (e) BS5, and (f) BS6. Brl, Beryl; Qtz, quartz.

\section{Methods}

All analyses were conducted at the Institute of Geology and Geophysics, Chinese Academy of Sciences (IGGCAS), Beijing, China.

For each sample, approximately 80 fragments, together with NIST SRM 610 glass, were selected and embedded in random orientations to form an epoxy resin mount for analysis. The mount was polished to obtain a flat surface and expose the interiors of the crystals.

The Raman spectra of the samples were performed using a LabRam micro-Raman spectrometer (Horiba Jobin Yvon, Paris, France), which was equipped with a Peltier cooled multichannel CCD detector and coupled with an Olympus BX41 petrographic microscope. A frequency-doubled Nd:YAG laser was used for excitation $(\lambda=532 \mathrm{~nm}$, output laser power on the sample is $15 \mathrm{~mW}$ ) with a grating of 600 lines $/ \mathrm{mm}$, a confocal hole set to $400 \mu \mathrm{m}$, 
and a slit width set to $100 \mu \mathrm{m}$. A charge-coupled device detector and a long workingdistance objective with a $50 \times$ magnification were used. The instrumental spectral resolution was $\sim 1 \mathrm{~cm}^{-1}$.

Electron probe microanalysis (EPMA) and backscattered electron (BSE) images were collected using a CAMECA SXFive FE electron microprobe (CAMECA, Paris, France), which was equipped with four wavelength dispersive spectrometers (WDS) after the mounts were cleaned and coated with carbon. Qualitative analyses were conducted using an acceleration voltage of $15 \mathrm{kV}$, a beam current of $20 \mathrm{nA}$, and a beam size of $5 \mu \mathrm{m}$. The elements were obtained using three crystals as follows: One TAP for $\mathrm{Na}, \mathrm{Mg}, \mathrm{Al}$, and $\mathrm{Si}$; one LLIF for Fe; and one LPET for K, Ca, Ti, and Cs. The standards used were albite for $\mathrm{Na}$; diopside for $\mathrm{Si}, \mathrm{Ca}$, and $\mathrm{Mg}$; hematite for $\mathrm{Fe}$; synthetic $\mathrm{TiO}_{2}$ for $\mathrm{Ti}$; orthoclase for $\mathrm{K}$; synthetic $\mathrm{Al}_{2} \mathrm{O}_{3}$ for $\mathrm{Al}$; and synthetic Cs-bearing glass for Cs. The peak counting time was $30 \mathrm{~s}$ for all elements, and the background counting time was $15 \mathrm{~s}$ on the highand low-energy background positions. Matrix compositional effects were corrected using the CAMECA software X-PHI correction method. Detection limits were in the range of $0.008 \sim 0.02$ wt. $\%(3 \sigma)$. The precision and accuracy for major and minor elements were better than $2 \%$ based on analyses of the internal laboratory standards. The analytical spots were located close to the SIMS pits to accurately document the compositional matrix effect.

Trace elements of the beryl samples were conducted by laser ablation inductively coupled plasma mass spectrometry (LA-ICP-MS). An Element XR HR-ICP-MS instrument (Thermo Fisher Scientific, Waltham, MA, USA) equipped with a $193 \mathrm{~nm}$ ArF excimer laser system (Geolas HD, Lambda Physik, Goettingen, Germany) was used. The analytical method was as described by Wu et al. [21]. A spot size of $60 \mu \mathrm{m}$ and a laser frequency of $5 \mathrm{~Hz}$ were used. External calibration was performed relative to NIST SRM 610 glass. USGS BCR-2G and ARM-1 glass were used for quality control monitoring [22]. Aluminum $\left({ }^{27} \mathrm{Al}\right)$ was used as an internal standard, which was independently determined using EMPA. The resulting data were reduced based on the GLITTER program [23]. For most trace elements $(>0.005 \mu \mathrm{g} / \mathrm{g})$, the accuracy was better than $\pm 10 \%$ with an analytical precision (1 RSD) of $\pm 10 \%$.

After re-polishing, the mounts were cleaned, dried, and coated with $\sim 20 \mathrm{~nm}$ of pure gold. The level of surface resistance was $<20 \Omega$ [24]. Beryl oxygen isotopes were measured using a CAMECA IMS-1280 SIMS (CAMECA, Paris, France). A detailed description of the instrumentation and the analytical procedures can be found in the work of Tang et al. [25]. The primary beam $\mathrm{Cs}^{+}$ions were accelerated at $10 \mathrm{kV}$ and focused in a Gaussian mode with an intensity of 1.0-2.0 nA. The analytical spot size was approximately $20 \mu \mathrm{m}$ squared (10 $\mu \mathrm{m}$ beam size $+10 \mu \mathrm{m}$ raster). The signals of ${ }^{16} \mathrm{O}$ and ${ }^{18} \mathrm{O}$ were simultaneously collected by two Faraday cups using a multi-collection mode. A normal electron gun was used to compensate for the charge effect. The measured ${ }^{18} \mathrm{O} /{ }^{16} \mathrm{O}$ ratios were normalized using Vienna Standard Mean Ocean Water compositions (VSMOW; ${ }^{18} \mathrm{O} /{ }^{16} \mathrm{O}=0.0020052$ ) as follows: Measured $\delta^{18} \mathrm{O}_{\text {VSMOW }}=\left(\left({ }^{18} \mathrm{O} /{ }^{16} \mathrm{O}\right)_{\text {Measured }} / 0.0020052-1\right) \times 1000$. Then, the IMF was corrected using BS1 as a reference material (IMF $=$ Measured $\delta^{18} \mathrm{O}_{\mathrm{VSMOW}}{ }^{(\mathrm{BS} 1)}$ - IRMS $\left.\delta^{18} \mathrm{O}_{\mathrm{VSMOW}}{ }^{(\mathrm{BS} 1)}\right)$. The $\delta^{18} \mathrm{O}$ of the other beryl samples was calculated as SIMS $\delta^{18} \mathrm{O}_{\text {VSMOW }(\text { sample })}=$ Measured $\left.\delta^{18} \mathrm{O}_{\text {VSMOW }(\text { sample })}-\mathrm{IMF}\right)$. The Isoplot 3.75 software package was used for data processing and calculations [26].

The oxygen isotopes of the BS1-BS6 beryl crystals were acquired using the laser-based fluorination oxygen extraction line at the Stable Isotope Laboratory. A New Wave Research MIR10-30 laser was coupled to a vacuum extraction system [27]. Each analysis consumed $\sim 2 \mathrm{mg}$. The beryl minerals were reacted with a purified $\mathrm{BrF}_{5}$ reagent in a chamber to generate oxygen. The gases were purified through a series of cryogenic traps held at the temperature of liquid nitrogen. The oxygen gas was then analyzed on a Finnigan MAT 252 isotopic ratio mass spectrometer. The results are reported in the conventional $\delta^{18} \mathrm{O}$ notation regarding VSMOW per mil. The Chinese national reference material GBW04409 (Penglai) was measured during this study as a quality monitor [28]. 


\section{Results and Discussion}

\subsection{Structural Study by Raman Spectroscopy}

Representative Raman spectra obtained from the analyzed samples are shown in Figure 3, which are very typical for beryl. All of the samples exhibited characteristic peaks near $\sim 322, \sim 395, \sim 527 \sim 684, \sim 1019$, and $\sim 1068 \mathrm{~cm}^{-1}$.

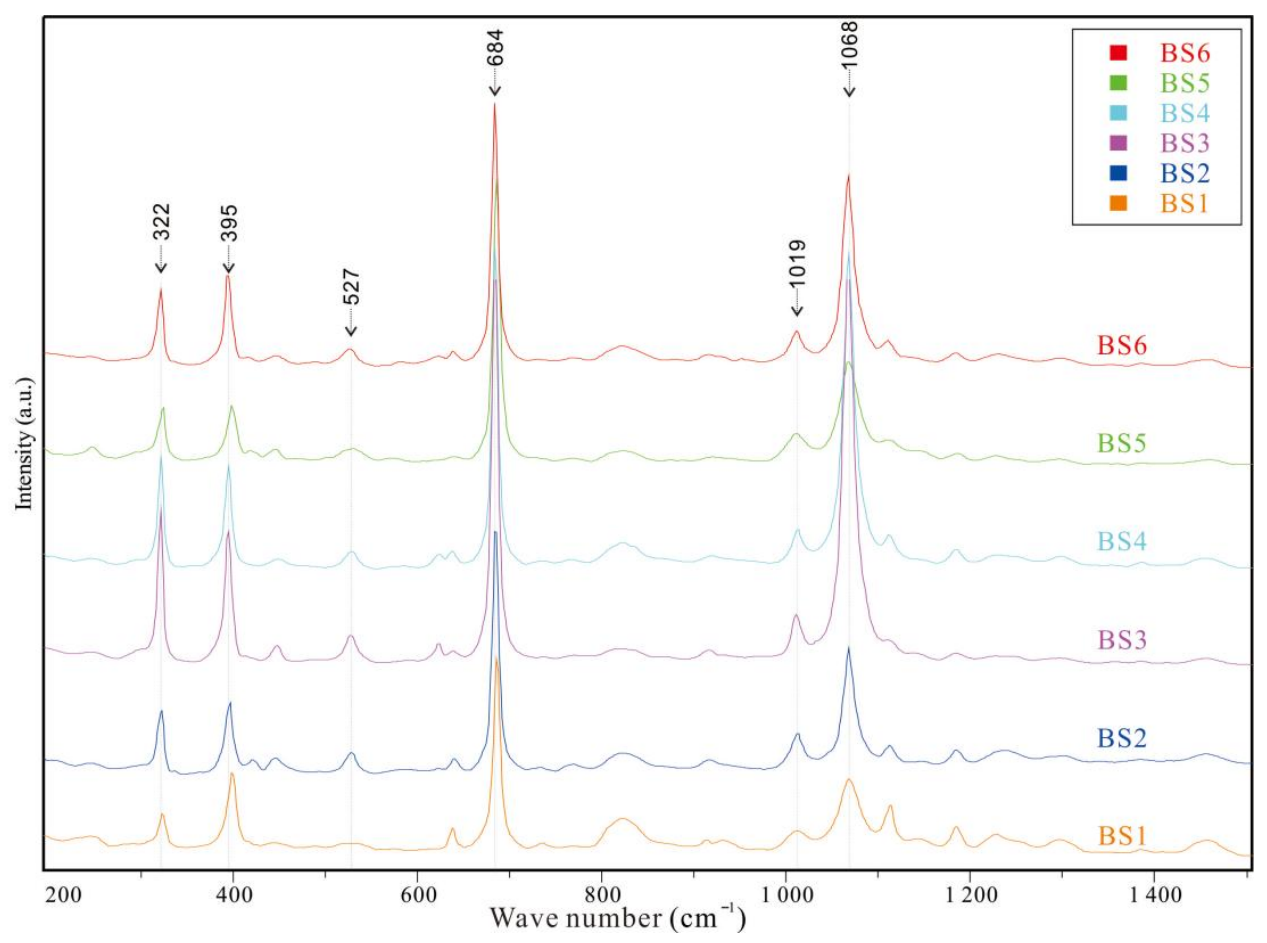

Figure 3. Raman spectra of the beryl samples. The main beryl Raman bands were found at $\sim 322$, $\sim 395, \sim 527, \sim 684, \sim 1019$, and $\sim 1068 \mathrm{~cm}^{-1}$.

The peaks below $1400 \mathrm{~cm}^{-1}$ are associated with beryl lattice phonon modes [29]. The strong peaks at $684 \mathrm{~cm}^{-1}$ and $1068 \mathrm{~cm}^{-1}$ are due to $\mathrm{Si}-\mathrm{O}$ vibrations. The modes at $322 \mathrm{~cm}^{-1}$ and $395 \mathrm{~cm}^{-1}$ are from Al-O bands. The two bands at $527 \mathrm{~cm}^{-1}$ and $1019 \mathrm{~cm}^{-1}$ represent Be-O vibrations [30,31].

\subsection{Chemical Composition}

The average values of the chemical composition data are summarized in Table 2, and the full results are presented in Supplementary Table S1. The studied samples did not show any regular zoning (Figure 2), with only small variations in the composition. The EPMA results show that the main contents of the six beryl samples are $\mathrm{SiO}_{2}, \mathrm{Al}_{2} \mathrm{O}_{3}$, and $\mathrm{BeO}$, which ranged from 66.0 to $67.0 \mathrm{wt} . \%, 17.9$ to $18.4 \mathrm{wt} . \%$, and 12.6 to $13.8 \mathrm{wt} . \%$, respectively. The total of the three main contents of the BS4 is more than $99 \mathrm{wt} . \%$. The main substitute elements in the beryl samples are $\mathrm{FeO}, \mathrm{Li}_{2} \mathrm{O}, \mathrm{Na}_{2} \mathrm{O}$, and $\mathrm{Cs}_{2} \mathrm{O}$, which ranged from $<0.1$ to $0.9 \mathrm{wt} . \%, 0.1$ to $0.7 \mathrm{wt} . \%, 0.2$ to $1.3 \mathrm{wt} . \%$, and $<0.1$ to $0.8 \mathrm{wt} . \%$, respectively.

The BS5 beryl is extremely poor in Fe, which was under the detection limit. BS1 and BS4 are very limited in $\mathrm{Fe}, \mathrm{Mg}$, and $\mathrm{Mn}(\leq 0.02 \mathrm{apfu})$. BS2, BS3, and BS6 contain slightly increased iron content, ranging from $\sim 4000$ to $\sim 5600 \mu \mathrm{g} / \mathrm{g}$. The LA-ICP-MS analyses show that the contents of $\mathrm{Li}, \mathrm{Rb}$, and Cs are the most enriched in BS5, which was up to $\sim 5095 \mu \mathrm{g} / \mathrm{g}, \sim 339 \mu \mathrm{g} / \mathrm{g}$, and $\sim 21,900 \mu \mathrm{g} / \mathrm{g}$, respectively. The results indicate that the major compositions and trace elements of these six samples are homogeneous, but the chemical compositions of each sample are different from those of other samples. 
Table 2. Quantitative element contents using EMPA and LA-ICP-MS for the beryl crystals used in this study.

\begin{tabular}{|c|c|c|c|c|c|c|c|c|c|c|c|c|}
\hline \multirow{2}{*}{$\begin{array}{c}\text { EMPA } \\
\text { wt. } \%\end{array}$} & \multicolumn{2}{|c|}{ BS1 $(n=25)$} & \multicolumn{2}{|c|}{ BS2 $(n=25)$} & \multicolumn{2}{|c|}{ BS3 $(n=25)$} & \multicolumn{2}{|c|}{ BS4 $(n=25)$} & \multicolumn{2}{|c|}{ BS5 $(n=25)$} & \multicolumn{2}{|c|}{ BS6 $(n=25)$} \\
\hline & Mean & $1 \mathrm{SD}$ & Mean & $1 \mathrm{SD}$ & Mean & $1 \mathrm{SD}$ & Mean & $1 \mathrm{SD}$ & Mean & $1 \mathrm{SD}$ & Mean & $1 \mathrm{SD}$ \\
\hline $\mathrm{SiO}_{2}$ & 66.15 & 0.55 & 66.63 & 0.87 & 66.80 & 0.90 & 67.05 & 0.93 & 66.01 & 0.76 & 66.89 & 0.67 \\
\hline $\mathrm{Al}_{2} \mathrm{O}_{3}$ & 17.88 & 0.19 & 18.09 & 0.13 & 18.06 & 0.24 & 18.41 & 0.15 & 18.13 & 0.15 & 17.86 & 0.11 \\
\hline $\mathrm{FeO}$ & 0.17 & 0.05 & 0.61 & 0.02 & 0.61 & 0.15 & 0.21 & 0.02 & 0.03 & 0.03 & 0.88 & 0.03 \\
\hline $\mathrm{MgO}$ & 0.11 & 0.06 & 0.00 & 0.01 & 0.14 & 0.12 & 0.01 & 0.03 & 0.00 & 0.01 & 0.13 & 0.02 \\
\hline $\mathrm{CaO}$ & 0.01 & 0.01 & 0.00 & 0.00 & 0.00 & 0.00 & 0.00 & 0.00 & 0.00 & 0.01 & 0.00 & 0.00 \\
\hline $\mathrm{BeO}_{\mathrm{cal}}$ & 12.65 & 0.23 & 13.63 & 0.18 & 13.72 & 0.21 & 13.77 & 0.35 & 12.75 & 0.30 & 13.69 & 0.15 \\
\hline $\mathrm{Li}_{2} \mathrm{O}_{\mathrm{cal}}$ & 0.66 & 0.14 & 0.14 & 0.01 & 0.11 & 0.04 & 0.11 & 0.15 & 0.59 & 0.15 & 0.13 & 0.03 \\
\hline $\mathrm{Na}_{2} \mathrm{O}$ & 1.26 & 0.29 & 0.19 & 0.03 & 0.20 & 0.08 & 0.21 & 0.29 & 1.02 & 0.36 & 0.27 & 0.06 \\
\hline $\mathrm{K}_{2} \mathrm{O}$ & 0.03 & 0.01 & - & - & 0.01 & 0.01 & - & - & 0.04 & 0.01 & - & - \\
\hline $\mathrm{Cs}_{2} \mathrm{O}$ & 0.40 & 0.10 & 0.41 & 0.02 & 0.11 & 0.08 & 0.04 & 0.10 & 0.78 & 0.67 & 0.01 & 0.01 \\
\hline Total & 99.33 & - & 99.72 & - & 99.75 & - & 99.82 & - & 99.35 & - & 99.88 & - \\
\hline $\mathrm{Si}$ & 6.00 & - & 6.00 & - & 6.00 & - & 6.00 & - & 6.00 & - & 6.00 & - \\
\hline $\mathrm{Be}_{\mathrm{cal}}$ & 2.76 & - & 2.95 & - & 2.96 & - & 2.96 & - & 2.79 & - & 2.95 & - \\
\hline $\mathrm{Li}_{\mathrm{cal}}$ & 0.24 & - & 0.05 & - & 0.04 & - & 0.04 & - & 0.21 & - & 0.05 & - \\
\hline sum & 3.00 & - & 3.00 & - & 3.00 & - & 3.00 & - & 3.00 & - & 3.00 & - \\
\hline $\mathrm{Al}$ & 1.91 & - & 1.92 & - & 1.91 & - & 1.94 & - & 1.94 & - & 1.89 & - \\
\hline $\mathrm{Fe}^{2+}$ & 0.01 & - & 0.05 & - & 0.05 & - & 0.02 & - & 0.00 & - & 0.07 & - \\
\hline $\mathrm{Mn}$ & 0.00 & - & 0.00 & - & 0.00 & - & 0.00 & - & 0.00 & - & 0.00 & - \\
\hline $\mathrm{Mg}$ & 0.01 & - & 0.00 & - & 0.02 & - & 0.00 & - & 0.00 & - & 0.02 & - \\
\hline sum & 1.94 & - & 1.97 & - & 1.98 & - & 1.96 & - & 1.94 & - & 1.97 & - \\
\hline $\mathrm{Ca}$ & 0.00 & - & 0.00 & - & 0.00 & - & 0.00 & - & 0.00 & - & 0.00 & - \\
\hline $\mathrm{Na}$ & 0.22 & - & 0.03 & - & 0.03 & - & 0.04 & - & 0.18 & - & 0.05 & - \\
\hline $\mathrm{K}$ & 0.00 & - & 0.00 & - & 0.00 & - & 0.00 & - & 0.00 & - & 0.00 & - \\
\hline Cs & 0.02 & - & 0.02 & - & 0.00 & - & 0.00 & - & 0.03 & - & 0.00 & - \\
\hline sum & 0.24 & - & 0.05 & - & 0.04 & - & 0.04 & - & 0.21 & - & 0.05 & - \\
\hline $\mathrm{Cs} / \mathrm{Na}$ & 0.07 & - & 0.49 & - & 0.16 & - & 0.04 & - & 0.21 & - & 0.01 & - \\
\hline $\mathrm{Mg} / \mathrm{Fe}$ & 1.04 & - & 0.01 & - & 0.38 & - & 0.10 & - & / & - & 0.26 & - \\
\hline \multirow{2}{*}{$\begin{array}{c}\text { LA-ICP-MS } \\
\mu \mathrm{g} / \mathrm{g}\end{array}$} & \multicolumn{2}{|c|}{ BS1 $(n=7)$} & \multicolumn{2}{|c|}{ BS2 $(n=7)$} & \multicolumn{2}{|c|}{ BS3 $(n=7)$} & \multicolumn{2}{|c|}{ BS4 $(n=7)$} & \multicolumn{2}{|c|}{ BS5 $(n=7)$} & \multicolumn{2}{|c|}{ BS6 $(n=10)$} \\
\hline & Mean & $1 \mathrm{SD}$ & Mean & $1 \mathrm{SD}$ & Mean & $1 \mathrm{SD}$ & Mean & $1 \mathrm{SD}$ & Mean & $1 \mathrm{SD}$ & Mean & $1 \mathrm{SD}$ \\
\hline $\mathrm{Li}$ & 3381 & 77 & 408 & 6 & 253 & 18 & 233 & 8 & 5095 & 68 & 87 & 5 \\
\hline $\mathrm{Rb}$ & 67 & 5 & 114 & 3 & 46 & 8 & 19 & 0.1 & 339 & 5 & 4 & 0.1 \\
\hline Cs & 3769 & 576 & 3653 & 88 & 1163 & 381 & 154 & 8 & 21,913 & 211 & 31 & 1 \\
\hline $\mathrm{Fe}$ & 1370 & 245 & 3983 & 144 & 5059 & 528 & 1417 & 34 & - & - & 5667 & 69 \\
\hline $\mathrm{Mn}$ & 72 & 9 & 72 & 2 & 105 & 20 & 84 & 2 & 19 & 1 & 126 & 5 \\
\hline $\mathrm{Mg}$ & 799 & 61 & 26 & 1 & 354 & 38 & 12 & 1 & - & - & 614 & 6 \\
\hline $\mathrm{Ti}$ & 197 & 8 & 219 & 7 & 218 & 3 & 218 & 4 & 193 & 2 & 219 & 3 \\
\hline $\mathrm{K}$ & 115 & 15 & - & - & 61 & 23 & - & - & 144 & 41 & - & - \\
\hline $\mathrm{P}$ & 94 & 5 & 128 & 10 & 122 & 7 & 121 & 7 & 112 & 7 & 120 & 5 \\
\hline $\mathrm{Zn}$ & 61 & 11 & 185 & 8 & 441 & 11 & 282 & 4 & 10 & 1 & 174 & 4 \\
\hline $\mathrm{Ga}$ & 24 & 3 & 31 & 1 & 25 & 1 & 11 & 0.1 & 13 & 1 & 19 & 0.1 \\
\hline $\mathrm{V}$ & 4 & 1 & 0.9 & 0.1 & - & - & 1.3 & 0.1 & - & - & 1.6 & 0.1 \\
\hline Sc & 2.2 & 0.7 & 1.3 & 0.1 & 0.5 & 0.1 & 0.5 & 0.1 & - & - & 0.6 & 0.1 \\
\hline Sn & 2.1 & 0.6 & 323.0 & 30 & - & - & - & - & - & - & - & - \\
\hline $\mathrm{Cu}$ & 1.4 & 0.1 & - & - & - & - & - & - & - & - & - & - \\
\hline $\mathrm{Ta}$ & - & - & - & - & - & - & - & - & 14.2 & 0.7 & - & - \\
\hline $\mathrm{Sr}$ & - & - & - & - & - & - & - & - & - & - & 0.5 & 0.4 \\
\hline $\mathrm{Ge}$ & - & - & - & - & - & - & - & - & 8.4 & 0.5 & - & - \\
\hline $\mathrm{Be}$ & 45,478 & 282 & 51,460 & 531 & 51,998 & 315 & 51,514 & 508 & 43,967 & 543 & 51,566 & 355 \\
\hline $\mathrm{Na}$ & 11,844 & 294 & 1400 & 27 & 1581 & 115 & 1117 & 30 & 6901 & 131 & 2375 & 82 \\
\hline
\end{tabular}

Analyses using EPMA are reported in wt. $\%$, and analyses using LA-ICP-MS are reported in $\mu \mathrm{g} / \mathrm{g}$. $\mathrm{BeO}_{\text {cal }}$ and $\mathrm{Li}_{2} \mathrm{O}_{\text {cal }}$ were calculated

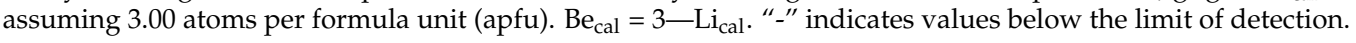




\subsection{Oxygen Isotopes Using SIMS and IRMS}

Oxygen isotopic determinations were carried out in two sessions to evaluate their micron-level homogeneity. In each session, NIST SRM 610 was analyzed to monitor the instrumental conditions. The analytical precision (2 standard deviations (SD)) of NIST SRM 610 were $0.28 \%$ and $0.42 \%$ in two sessions, respectively, representing the instrument's stability in both sessions. The first session was carried out to identify the inter-grain variation in oxygen isotopes, performed as individual measurements on 35 BS1, 34 BS2, 18 BS3, 32 BS4, 32 BS5, and 35 BS6 shards, respectively. The second session was designed to examine intra-grain variability. Two to four spots were performed on each shard. The second session consisted of 39 BS1, 40 BS2, 32 BS3, 40 BS4, 34 BS5, and 40 BS6 measurements on 15 grains of each beryl sample. The raw data of the two sessions are attached as Supplementary Table S2, and the summarized SIMS data are presented in Table 3.

Table 3. The oxygen isotopes obtained by IRMS and SIMS.

\begin{tabular}{cccccccccc}
\hline Methods & \multicolumn{3}{c}{ IRMS } & \multicolumn{7}{c}{ SIMS/Standard: BS1 } \\
\hline Time & & $\mathbf{2 0 2 1}$ & \multicolumn{2}{c}{ 2019-12-20 } & \multicolumn{3}{c}{$\mathbf{2 0 2 1 - 7 - 2 0}$} \\
\hline Sample & Mean & 2 SD & $n$ & Mean & 2 SD & $n$ & Mean & 2 SD & $n$ \\
\hline BS1 & 15.01 & 0.34 & 14 & 15.01 & 0.39 & 35 & 15.01 & 0.38 & 39 \\
\hline BS2 & 7.53 & 0.16 & 3 & 7.31 & 0.26 & 34 & 7.30 & 0.24 & 40 \\
\hline BS3 & 10.71 & 0.22 & 3 & 10.75 & 0.34 & 18 & 10.80 & 0.44 & 32 \\
\hline BS4 & 2.38 & 0.14 & 3 & 2.36 & 0.22 & 32 & 2.58 & 0.20 & 40 \\
\hline BS5 & 10.72 & 0.44 & 3 & 10.98 & 0.36 & 32 & 10.94 & 0.34 & 34 \\
\hline BS6 & 6.35 & 0.56 & 3 & 6.23 & 0.32 & 35 & 6.52 & 0.20 & 40 \\
\hline
\end{tabular}

The measured values of $\delta^{18} \mathrm{O}$ of the six samples during each session formed a Gaussian distribution (Figure 4). The $2 \mathrm{SD}$ of the results got from the beryl minerals ranged from $0.22 \%$ to $0.40 \%$. It is noted that the measured apparent values of $\delta^{18} \mathrm{O}$ of the six samples in the first session are quite different from those in the second session (Figure 4a-1), which demonstrates the importance of matrix-matched reference materials.

Homogeneity can be estimated using the standard deviation of the measured results. In a session, $1 \mathrm{SD}$ for zircon standards was routinely $0.15 \%-0.25 \%$ [32]. SIMS oxygen analysis can achieve excellent repeatability $(<0.15 \%)$, as only the measurement condition is perfect $[33,34]$. These results suggest that the intra- or inter-grain variations in oxygen isotopes are small enough to demonstrate the homogeneity of these beryl samples. Among them, samples BS2 (2 SD $=0.26 \%$ (Figure $4 \mathrm{c}$ ) and $=0.24 \%$ (Figure $4 \mathrm{~d})$ ) and BS4 ( $2 \mathrm{SD}=0.22 \%$ (Figure $4 \mathrm{~g}$ ) and $=0.20 \%$ (Figure $4 \mathrm{~h}$ ) ) show the lowest variation. 


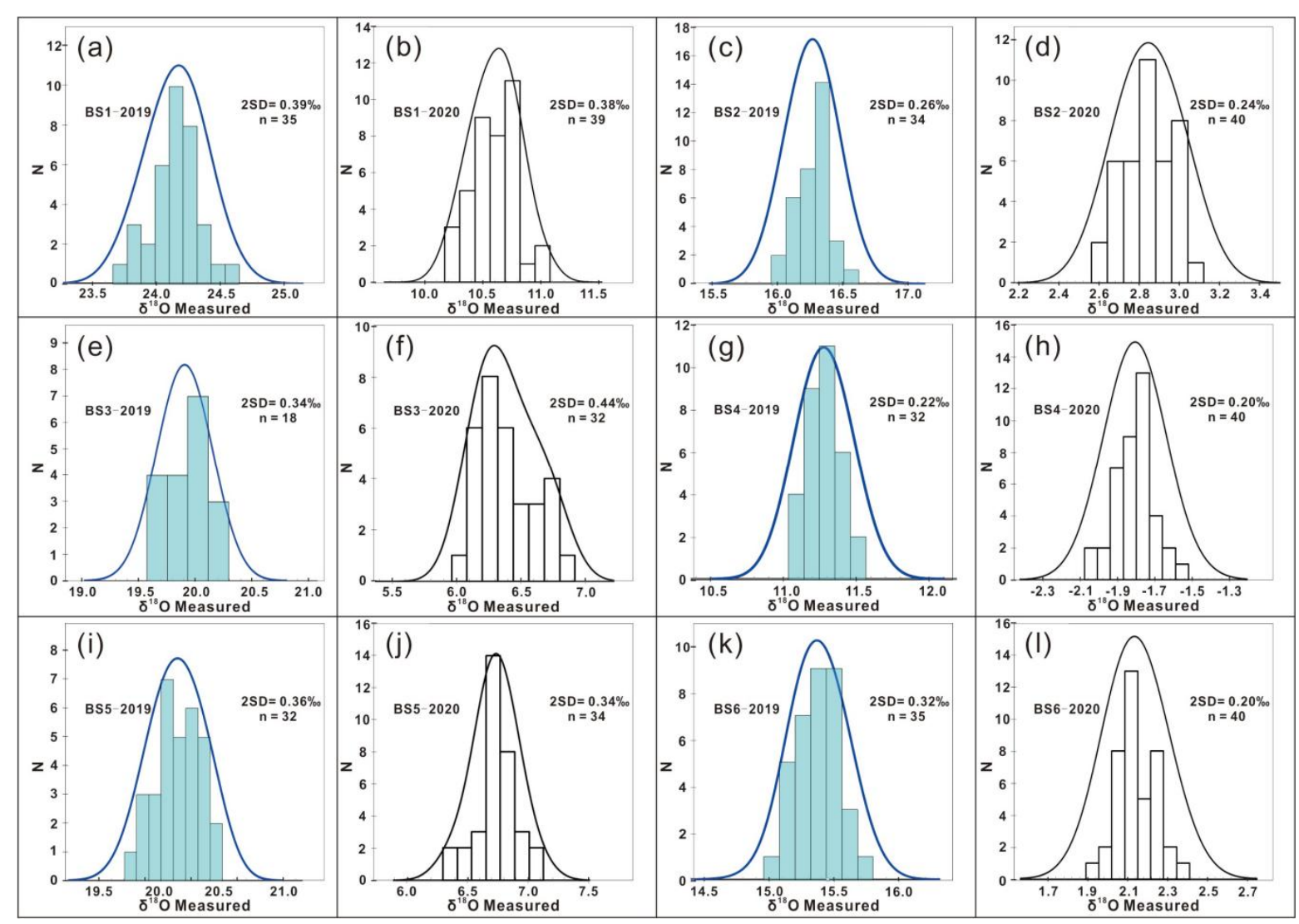

Figure 4. Frequency distributions of SIMS-measured apparent $\delta^{18} \mathrm{O}$ values of the six beryl samples: $(\mathbf{a}, \mathbf{c}, \mathbf{e}, \mathbf{g}, \mathbf{i}, \mathbf{k})$ are the SIMS-measured apparent values of $\delta^{18} \mathrm{O}$ of BS1, BS2, BS3, BS4, BS5, and BS6, respectively, in the first session; $(\mathbf{b}, \mathbf{d}, \mathbf{f}, \mathbf{h}, \mathbf{j}, \mathbf{l})$ are the SIMS-measured apparent values of $\delta^{18} \mathrm{O}$ of BS1, BS2, BS3, BS4, BS5, and BS6, respectively, in the second session.

The oxygen isotope compositions obtained by the laser fluorination technique are attached as Supplementary Table S3 and are summarized in Table 3. Twenty-nine aliquots of the six beryl samples were analyzed. A total of 14 analyses were performed on BS1, including eight BS-1 shards and six BS-2 shards. Three analyses were carried out for each of the other five samples (BS2-BS6). The recommended values for BS1, BS2, BS3, BS4, BS5, and BS6 are $15.01 \pm 0.34 \%$ o $(n=14$; Figure 5 A1), $7.53 \pm 0.16 \%$ o $(n=3$; Figure $5 \mathrm{~B} 1), 10.71 \pm 0.22 \%$ o $(n=3$; Figure $5 \mathrm{C} 1), 2.38 \pm 0.14 \%$ o $(n=3$; Figure $5 \mathrm{D} 1), 10.72 \pm 0.44 \%$ o $(n=3$; Figure $5 \mathrm{E} 1)$, and $6.35 \pm 0.56 \%$ o $(n=3$; Figure $5 \mathrm{~F} 1)$, respectively. The relatively large standard deviation ( $2 \mathrm{SD}=0.56 \%$ ) for BS6 was most likely due to the abundant quartz inclusions.

Then, the SIMS IMF was corrected using BS1 RM as reference material with a $\delta^{18} \mathrm{O}$ value of $15.01 \%$. There is an excellent linear relationship between the SIMS $\delta^{18} \mathrm{O}$ values and the IRMS $\delta^{18} \mathrm{O}$ values $\left(R^{2}=0.99\right)$ (Figure 6). This means that the SIMS $\delta^{18} \mathrm{O}$ values corrected by one reference material are consistent with the IRMS $\delta^{18} \mathrm{O}$ value within analytical uncertainty. Thereby, no matrix effect related to composition variation was present in the beryl SIMS oxygen isotope analysis. 


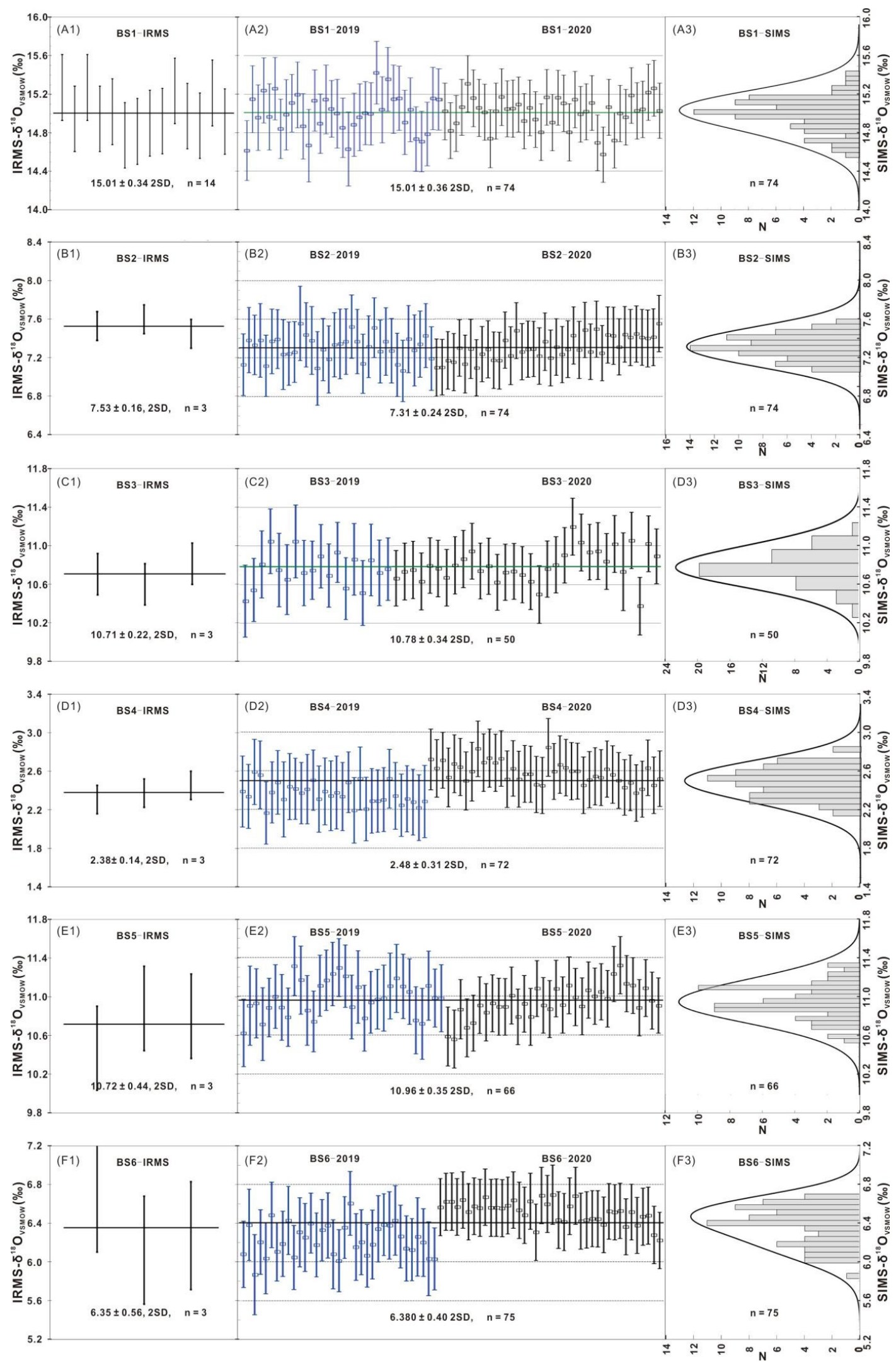

Figure 5. The laser fluorination isotope ratio mass spectrometry (IRMS) values of the six beryl samples and the SIMS $\delta{ }^{18} \mathrm{O}$ $(\%)$ values of these samples, which were normalized to the IRMS value of BS1: (A1-F1) are the IRMS $\delta^{18} \mathrm{O}$ mean values of BS1, BS2, BS3, BS4, BS5, and BS6, respectively; (A2-F2) are the SIMS $\delta^{18} \mathrm{O}$ mean values of BS1, BS2, BS3, BS4, BS5, and BS6, respectively; (A3-F3) are the frequency distributions of SIMS $\delta^{18} \mathrm{O}$ values of BS1, BS2, BS3, BS4, BS5, and BS6, respectively. 


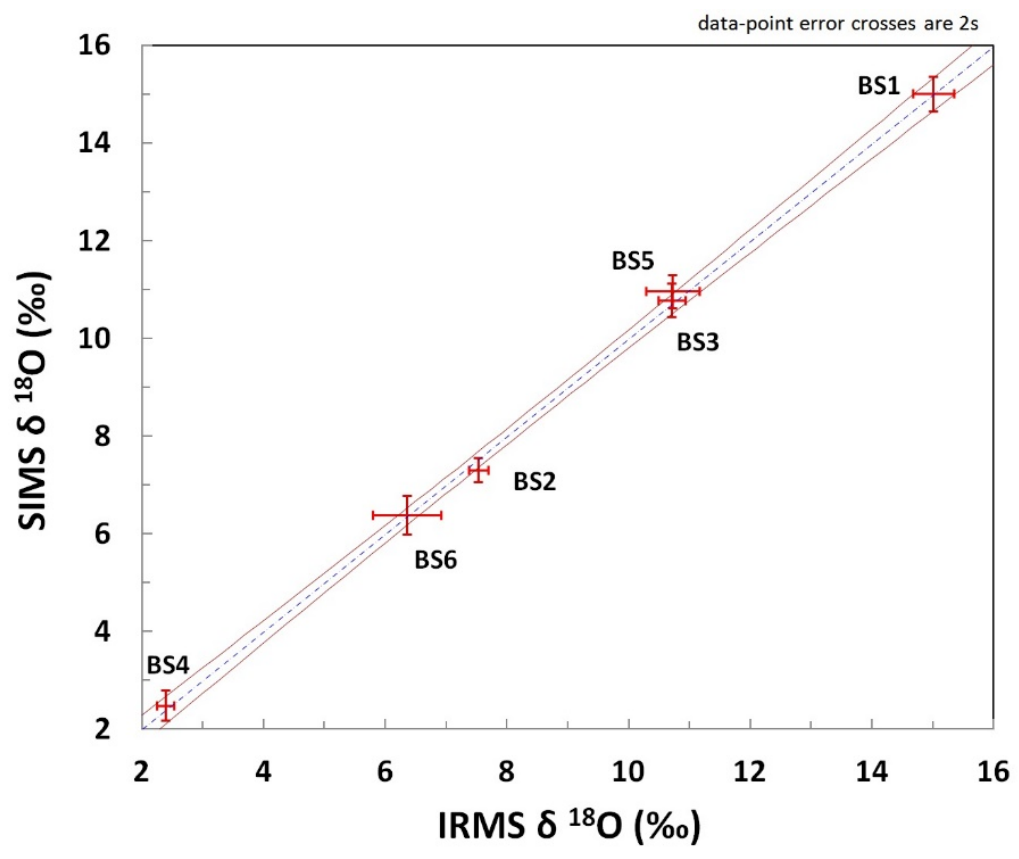

Figure 6. $\delta^{18} \mathrm{O}$ (SIMS) vs. $\delta^{18} \mathrm{O}$ (IRMS) of the six samples.

\section{Conclusions}

This study evaluated six natural beryl samples using Raman, EMPA, SIMS, and IRMS. Samples BS1, BS2, BS4, and BS5 were shown to be pure and clean (Figures 1 and 2). The SIMS results of BS1 ( $2 \mathrm{SD}=0.36 \%, n=74)$, BS2 ( $2 \mathrm{SD}=0.24 \%, n=74)$, BS4 ( $2 \mathrm{SD}=0.31 \%$, $n=72)$, and BS5 ( $2 \mathrm{SD}=0.35 \%, n=72)$ during the two sessions suggest that the samples are homogeneous in terms of oxygen isotope composition at a micrometer level. They all meet the criteria for use as reference materials for SIMS oxygen isotopic analysis. Compared to the IRMS results, this study showed no matrix effect related to composition variation in the beryl SIMS oxygen isotope analysis. The recommended $\delta^{18} \mathrm{O}$ values of the four reference materials, BS1, BS2, BS4, and BS5, are $15.01 \pm 0.34 \%$ ( 2 SD), $7.53 \pm 0.16 \%$ ( 2 SD), $2.38 \pm 0.14 \%$ o (2 SD), and $10.72 \pm 0.44 \%$ o (2 SD), respectively. The BS2 and BS4 beryl samples showed the smallest variation and are thus the most suitable reference materials.

All of the beryl materials are available upon request from the corresponding author.

Supplementary Materials: The following are available online at https:/ / www.mdpi.com/article/ 10.3390/cryst11111322/s1, Supplementary Table S1: The chemical composition data of the beryl samples; Supplementary Table S2: The oxygen isotopes obtained using SIMS; Supplementary Table S3: The oxygen isotopes obtained using IRMS.

Author Contributions: Data analysis and writing, X.L. (Xiaoxiao Ling) and Q.L.; IRMS study, L.F. and T.L.; SIMS study, Y.L. (Yu Liu), G.T., and J.L.; EPMA study, D.Z.; LA-ICP-MS study, S.W.; Raman spectra study, L.H.; samples, Y.L. (Yan Liu) and R.W.; supervision, X.L. (Xianhua Li); funding acquisition, X.L. (Xianhua Li) and Q.L. All authors have read and agreed to the published version of the manuscript.

Funding: This work was supported by the National Key Research and Development Plan (No. 2018YFA0702600) and the National Natural Science Foundation of China (No. 41773044, 41773047, and 41673059).

Institutional Review Board Statement: Not applicable.

Informed Consent Statement: Not applicable.

Data Availability Statement: Not applicable.

Acknowledgments: The authors thank M.L. Ouyang, Z.G. Liu, J. Jiang, and D.N. Wang for providing the samples from Nigeria, Myanmar, and Brazil. They also thank H.X. Ma, L.Z. Guo, and K.H. Zhao 
for technical assistance. Constructive discussions with L. Xie and F. Liu greatly improved the paper. Lastly, the authors gratefully acknowledge the detailed reviews from the editor and the reviewers.

Conflicts of Interest: The authors declare that they have no known competing financial interests or personal relationships that could have influenced the work reported in this paper.

\section{References}

1. Hofstra, A.H.; Kreiner, D.C. Systems-Deposits-Commodities-Critical Minerals Table for the Earth Mapping Resources Initiative (ver. 1.1, May 2021); U.S. Geological Survey Open-File Report 2020-1042; U.S. Geological Survey: Reston, VA, USA, 2020; 26p.

2. Wang, R.; Wu, B.; Xie, L.; Che, X.; Xiang, L.; Liu, C. Global tempo-spatial distribution of rare-metal mineralization and continental evolution. Acta Geol. Sin. 2021, 95, 182-193.

3. Ottaway, T.L.; Wicks, F.J.; Bryndzia, L.T.; Kyser, T.K.; Spooner, E.T.C. Formation of the Muzo hydrothermal emerald deposit in Colombia. Nat. Cell Biol. 1994, 369, 552-554. [CrossRef]

4. Cérný, P. Mineralogy of Beryllium in Granitic Pegmatites. Rev. Miner. Geochem. 2002, 50, 405-444. [CrossRef]

5. Tao, X.; Xie, L.; Wang, R.; Zhang, R.; Hu, H.; Liu, C. Mineralogical characteristics of beryl: A case study of the beryls from Cuona and Qomolangma district in Himalaya. J. Nanjing Univ. 2020, 56, 815-829. [CrossRef]

6. Wu, F.-Y.; Liu, X.-C.; Liu, Z.-C.; Wang, R.-C.; Xie, L.; Wang, J.-M.; Ji, W.-Q.; Yang, L.; Liu, C.; Khanal, G.P.; et al. Highly fractionated Himalayan leucogranites and associated rare-metal mineralization. Lithos 2020, 352-353, 105319. [CrossRef]

7. Zhou, Q.; Qin, K.; Tang, D. Mineralogy of columbite-group minerals from the rare-element pegmatite dykes in the East-Qinling orogen, Central China: Implications for formation times and ore genesis. J. Asian Earth Sci. 2021, 27, 104879. [CrossRef]

8. Onuma, N.; Clayton, R.N.; Mayeda, T.K. Oxygen Isotope Fractionation between Minerals and an Estimate of the Temperature of Formation. Science 1970, 167, 536-538. [CrossRef]

9. Taylor, R.P.; Fallick, A.E.; Breaks, F.W. Volatile Evolution in archean rare-element granitic pegmatites-Evidence from the hydrogen isotopic composition of channel $\mathrm{H}_{2} \mathrm{O}$ in beryl. Can. Mineral. 1992, 30, 877-893.

10. Galili, N.; Shemesh, A.; Yam, R.; Brailovsky, I.; Sela-Adler, M.; Schuster, E.M.; Collom, C.; Bekker, A.; Planavsky, N.; Macdonald, F.A.; et al. The geologic history of seawater oxygen isotopes from marine iron oxides. Science 2019, 365, 469-473. [CrossRef]

11. Giuliani, G.; France-Lanord, C.; Coget, P.; Schwarz, D.; Cheilletz, A.; Branquet, Y.; Giard, D.; Martin-Izard, A.; Alexandrov, P.; Piat, D.H. Oxygen isotope systematics of emerald: Relevance for its origin and geological significance. Miner. Depos. 1998, 33, 513-519. [CrossRef]

12. Giuliani, G.; Chaussidon, M.; Schubnel, H.-J.; Piat, D.H.; Rollion-Bard, C.; France-Lanord, C.; Giard, D.; de Narvaez, D.; Rondeau, B. Oxygen Isotopes and Emerald Trade Routes Since Antiquity. Science 2000, 287, 631-633. [CrossRef]

13. Ireland, T.R. Considerations in Zircon Geochronology by SIMS. Rev. Miner. Geochem. 2003, 53, 215-241. [CrossRef]

14. Isa, J.; Kohl, I.; Liu, M.-C.; Wasson, J.; Young, E.; McKeegan, K. Quantification of oxygen isotope SIMS matrix effects in olivine samples: Correlation with sputter rate. Chem. Geol. 2017, 458, 14-21. [CrossRef]

15. Scicchitano, M.R.; Rubatto, D.; Hermann, J.; Majumdar, A.S.; Putnis, A. Oxygen isotope analysis of olivine by ion microprobe: Matrix effects and applications to a serpentinised dunite. Chem. Geol. 2018, 499, 126-137. [CrossRef]

16. Vho, A.; Rubatto, D.; Putlitz, B.; Bouvier, A. New Reference Materials and Assessment of Matrix Effects for SIMS Measurements of Oxygen Isotopes in Garnet. Geostand. Geoanalytical Res. 2020, 44, 459-471. [CrossRef]

17. Eiler, J.M.; Graham, C.; Valley, J. SIMS analysis of oxygen isotopes: Matrix effects in complex minerals and glasses. Chem. Geol. 1997, 138, 221-244. [CrossRef]

18. Tang, G.; Su, B.; Li, Q.; Xia, X.; Jing, J.; Feng, L.; Martin, L.; Yang, Q.; Li, X. High-Mg\# Olivine, Clinopyroxene and Orthopyroxene Reference Materials for In Situ Oxygen Isotope Determination. Geostand. Geoanalytical Res. 2019, 43, 585-593. [CrossRef]

19. Lum, J.E.; Viljoen, F.; Cairncross, B.; Frei, D. Mineralogical and geochemical characteristics of Beryl (Aquamarine) from the Erongo Volcanic Complex, Namibia. J. Afr. Earth Sci. 2016, 124, 104-125. [CrossRef]

20. Liu, Y.; Deng, J.; Shi, G.; Sun, D. Geochemical and morphological characteristics of coarse-grained tabular beryl from the Xuebaoding W-Sn-Be deposit, Sichuan Province, western China. Int. Geol. Rev. 2012, 54, 1673-1684. [CrossRef]

21. Wu, S.; Karius, V.; Schmidt, B.C.; Simon, K.; Wörner, G. Comparison of Ultrafine Powder Pellet and Flux-free Fusion Glass for Bulk Analysis of Granitoids by Laser Ablation-Inductively Coupled Plasma-Mass Spectrometry. Geostand. Geoanalytical Res. 2018, 42, 575-591. [CrossRef]

22. Wu, S.; Wörner, G.; Jochum, K.P.; Stoll, B.; Simon, K.; Kronz, A. The Preparation and Preliminary Characterisation of Three Synthetic Andesite Reference Glass Materials (ARM-1, ARM-2, ARM-3) for In Situ Microanalysis. Geostand. Geoanalytical Res. 2019, 43, 567-584. [CrossRef]

23. Griffin, W.; Powell, W.; Pearson, N.J.O.; Reilly, S. GLITTER: Data reduction software for laser ablation ICP-MS. In Laser AblationICP-MS in the Earth Sciences: Current Practices and Outstanding Issues; Sylvester, P., Ed.; Mineralogical Association of Canada: Québec, QC, Canada, 2008; pp. 308-311.

24. Li, X.H.; Liu, Y.; Li, Q.L.; Guo, C.H.; Chamberlain, K.R. Precise determination of Phanerozoic zircon Pb/Pb age by multi-collector SIMS without external standardization. Geochem. Geophys. Geosyst. 2009, 10, Q04010. [CrossRef]

25. Tang, G.-Q.; Liu, Y.; Feng, L.-J.; Wei, G.-J.; Su, W.; Li, Y.; Ren, G.-H.; Li, X.-H. New Natural and Fused Quartz Reference Materials for Oxygen Isotope Microanalysis. At. Spectrosc. 2020, 41, 41. [CrossRef] 
26. Ludwig, K.R. User's Manual for Isoplot 3.75, A Geochronological Tooklit for Microsoft Excel; Berkeley Geochronology Center Special Publication: Berkeley, CA, USA, 2012.

27. Feng, L.; Li, H.; Li, T. Potential Reference Materials for Hematite Oxygen Isotope Analysis. Minerals 2020, 10, 987. [CrossRef]

28. Li, X.-H.; Long, W.-G.; Li, Q.; Liu, Y.; Zheng, Y.-F.; Yang, Y.-H.; Chamberlain, K.R.; Wan, D.-F.; Guo, C.-H.; Wang, X.-C.; et al. Penglai Zircon Megacrysts: A Potential New Working Reference Material for Microbeam Determination of Hf-O Isotopes and U-Pb Age. Geostand. Geoanalytical Res. 2010, 34, 117-134. [CrossRef]

29. Kim, C.C.; Bell, M.; McKeown, D. Vibrational analysis of beryl (Be3Al2Si6O18) and its constituent ring (Si6O18). Phys. B Condens. Matter 1995, 205, 193-208. [CrossRef]

30. Hagemann, H.; Lucken, A.; Bill, H.; Gysler-Sanz, J.; Stalder, H. Polarized Raman spectra of beryl and bazzite. Phys. Chem. Miner. 1990, 17, 395-401. [CrossRef]

31. Wang, P.; Gray, T.P.; Li, Z.; Anderson, E.J.D.; Allaz, J.; Smyth, J.R.; Koenig, A.E.; Qi, L.; Zhou, Y.; Raschke, M.B. Mineralogical classification and crystal water characterisation of beryl from the W-Sn-Be occurrence of Xuebaoding, Sichuan province, western China. Miner. Mag. 2021, 85, 172-188. [CrossRef]

32. Tang, G.-Q.; Li, X.-H.; Li, Q.-L.; Liu, Y.; Ling, X.-X.; Yin, Q.-Z. Deciphering the physical mechanism of the topography effect for oxygen isotope measurements using a Cameca IMS-1280 SIMS. J. Anal. At. Spectrom. 2015, 30, 950-956. [CrossRef]

33. Peres, P.; Kita, N.T.; Valley, J.W.; Fernandes, F.; Schuhmacher, M. New sample holder geometry for high precision isotope analyses. Surf. Interface Anal. 2013, 45, 553-556. [CrossRef]

34. Treble, P.; Schmitt, A.; Edwards, R.; McKeegan, K.; Harrison, T.; Grove, M.; Cheng, H.; Wang, Y. High resolution Secondary Ionisation Mass Spectrometry (SIMS) $818 \mathrm{O}$ analyses of Hulu Cave speleothem at the time of Heinrich Event 1. Chem. Geol. 2007, 238, 197-212. [CrossRef] 